\title{
Visual Perceptual Deficits in Different Types of Cerebral Palsy
}

\author{
*Sharna Berelowitz; BSc. OT (Wits) MSc. OT (Wits). https://orcid.org/0000-0002-9294-8354 \\ Occupational Therapist, Forest Town School. Postgraduate student, Department of Occupational Therapy, School of therapeutic Sciences, \\ Faculty of Health Sciences, University of Witwatersrand
}

\section{Denise Franzsen; BSc. OT (Wits) MSc. OT (Wits) PhD (Wits) DHT (Pre). http://orcid.org/0000-000 I-8295-6329}

Sessional Senior Lecturer. Department of Occupational Therapy, School of therapeutic Sciences, Faculty of Health Sciences, University of Witwatersrand

Introduction: Children with cerebral palsy (CP) have been found to present with visual perceptual impairments (VPI). Research indicates differences in VPI in various subtypes of CP. However, visual perceptual deficits in children with CP has not been investigated in terms of occupational therapy assessment and treatment in a South African context. The purpose of this study was to determine the specific VPI in learners aged 4- 8 years with various subtypes of CP attending a school for learners with special needs in Johannesburg, South Africa. Method: The Test of Visual Perceptual Skills $3^{\text {rd }}$ ed. (TVPS-3) was used to assess 80 learners. Their subtest scores and composite scores were compared according to their subtype of CP as well as other demographic variables including age, and the Gross Motor Function Classification System (GMFCS) level.

Results: All the subtypes of CP were found to present with VPI, with the right spastic unilateral (hemiplegic) group having the fewest number of impairments and the ataxic group the greatest number of impairments. A significant difference in visual discrimination and figure ground scores were found based on the subtype of CP while the Basic Processes composite scores on the TVPS-3 differed significantly for both the subtypes of CP and gender. No significant differences were found for VPI based on age and GMFCS levels. Conclusion: Visual perceptual impairments were found in a high percentage of participants with $C P$ with significant differences between the subtypes of CP and according to gender but not for age and GMFCS levels.

Key words: Cerebral Palsy, Visual Perception, TVPS-3, Visual Perceptual Impairment, Occupational Therapy, Gross Motor Function Classification System

\section{INTRODUCTION}

Cerebral palsy (CP) occurs as a result of an early, non-progressive lesion to the central nervous system (CNS) in children. These children present with a variety of different developmental disorders depending on the area of the lesion in the brain'. Visual perceptual ability is one of the many areas that is often impaired in children with CP. Schmetz et al ${ }^{2}$ confirmed that children with CP aged 5- I8 years have persistent deficits in visual perception or visual perceptual impairment (VPI) compared to typical children of similar age and nonverbal IQ 2 .

Ego et $\mathrm{al}^{3}$. indicate that there is no accepted prevalence rate of visual perceptual impairment (VPI) in children with $C \mathrm{P}^{3}$ due to different lesion patterns in the brain. These children present with different aetiological factors and clinical characteristics, so the type of visual perceptual deficits and the degree of impairment differ from child to child with CP. These differences have been associated with the different subtypes of $\mathrm{CP}^{3}$. Perceptual deficits have functional implications for children with $\mathrm{CP}$ and can affect their academic performance in reading ability and learning ${ }^{4}$ as well as their activities of daily living (ADL's) such as dressing ${ }^{5}$. It is therefore essential that the visual perceptual skills of children with $C P$ are assessed in order $^{6}$ to improve performance in these functional activities. Occupational therapists address these visual perceptual impairments in children with $\mathrm{CP}$ using a bottom up approach to remediate the deficits with the goal of allowing the child to participate optimally at home, at school and in their community ${ }^{7}$.

Initial studies completed in the 1960s - in which perceptual assessments were administered to children with dyskinetic, bilateral spastic and unilateral spastic (right and left) CP - indicated differences in VPI in children with various subtypes of $\mathrm{CP}^{8}$. In their systematic review in 2015 Ego et al. ${ }^{3}$ recommend that further research on the differences of visual perceptual impairment in the different subtypes of $\mathrm{CP}$ be conducted with a larger number of participants, since a limited number of studies have considered these differences ${ }^{3,8-11}$. Gaining a better understanding of the specific visual perceptual impairments for each subtype of CP will in turn allow occupational therapists to provide specifically targeted intervention. This is particularly true in South Africa where resources for the treatment of children with $\mathrm{CP}$ are limited, especially in the public sector where caseloads are high ${ }^{12}$. In these settings, it is often necessary to treat children in groups rather than individual sessions. Determining whether specific visual perceptual impairments are more likely to occur in different subtypes of $\mathrm{CP}$ will also allow for easier clustering of children for group therapy.

The subtypes of CP are classified using the Surveillance of Cerebral Palsy in Europe (SCPE) ${ }^{13}$, which is a standardised classification of CP that is now used internationally. It was developed according to motor deficits with which the child presents. The classification identified three main subtypes of CP: spastic, dys- 
kinetic and ataxic ${ }^{13}$. Spastic (unilateral and bilateral) CP is the most common clinical subtype found in near or full-term infants whereas in preterm and very preterm infants, spastic (bilateral) diplegia is more common ${ }^{14}$. Spastic CP occurs due to damage to the cortex ${ }^{15}$ and the cortical spinal tract (pyramidal tract) and the sensory pathways ${ }^{16}$. Seventy percent of children with $C P$ have spastic or mixed forms of the condition where more than one type of motor pattern is present, resulting in spastic bilateral diplegia, quadriplegia or spastic unilateral hemiplegia ${ }^{16}$. Spastic bilateral (upper limb and lower limb (UL and LL) CP resulting in quadriplegia is associated with global hypoxic-ischemia events, intrauterine infection, and metabolic disorders. Children born prematurely with periventricular leukomalacia and mal-development of periventricular oligodendrocytes (specifically in the corticospinal fibres innervating the lumbosacral segments) present with spastic bilateral (lower limb (LL) or diplegic $\mathrm{CP}^{17}$. Spastic unilateral (right or left) $\mathrm{CP}$ results in hemiplegia due to a focal pathology that occurs as a result of unilateral cerebral and cortical-subcortical lesions. The cause of unilateral CP correlates to isolated porencephalic cysts, internal capsule lesions, periventricular lesions or damage to the cerebral hemisphere ${ }^{18}$. Thirty percent of children with CP have extrapyramidal (dyskinetic) forms which include dystonic, rigid, choreo, ataxic and hypotonic $\mathrm{CP}$ and which occur as a result of damage to the pathways between the cortex and the basal ganglia $^{16}$. Choreo-athetotic and dystonic CP have been found to correlate with perinatal asphyxia and hyperbilirubinemia. Ataxia $\mathrm{CP}$ is the least common type of $\mathrm{CP}$ and is caused by damage to the cerebellum and cerebellar pathways ${ }^{15,18}$.

The different cerebral lesions responsible for the subtypes of CP (according to the SCPE classification) result in comorbid cognitive impairments. In the definition of Cerebral Palsy by Rosenbaum, the motor disorders are often accompanied by disturbances of perception ${ }^{19}$. Stiers et al. ${ }^{20}$ concluded that visual perception deficits are related to a different location of damage in the brain and the vulnerability of visual neural structures at birth ${ }^{20}$. Other factors such as motor dysfunction assessed on the Gross Motor Function Classification System (GMFCS) also have no correlation to VPI and Hamid et al. reported that the severity of gross motor functioning does not directly impact on the visual perceptual skills of children with $\mathrm{CP}^{9}$. Verbal intelligence scores have also not been found to be associated with VPI in children with $\mathrm{CP}^{21}$. Although attention, language or memory ${ }^{3}$ may differ according to the subtype of $\mathrm{CP}$, only impairments related to visual perception were considered for this study.

Studies have reported VPI in children with $\mathrm{CP}^{2,3,22}$ as a result of a malfunctioning of the associative visual systems rather than the posterior visual pathways ${ }^{23}$. A systematic review by Ego et al. ${ }^{3}$ reported that $40 \%-50 \%$ of children with CP presented with VPI with a mean perception quotient of 70 to 90 , indicating visual perceptual dysfunction must be considered as a core issue in children with $\mathrm{CP}^{3}$. Challenges with visual perception have been associated with white matter injury, right-sided brain lesions, preterm birth, and spastic diplegic CP with the intensity of the visual perceptual deficits being associated with different subtypes of $\mathrm{CP}^{3}$. Associated visual defects in children with $\mathrm{CP}^{2}$ can be caused by periventricular leukomalacia, intraventricular haemorrhage, hypoxic ischaemic encephalopathy or a cerebral infarction ${ }^{18}$. Thus, even when deficits in acuity is accommodated with spectacles in children with $\mathrm{CP}$, other factors such as visual fields, eye movements and binocular nystagmus ${ }^{24}$ might also influence the child's visual perceptual skills.

When assessing VPI in children with CP, Abercrombie ${ }^{8}$ found that children with dyskinetic CP had fewer VPIs than spastic children, therefore indicating that VPI may be associated with CP where spasticity is the predominant sign ${ }^{8}$. Children in the spastic bilateral (UL and LL as well as LL only) and left spastic unilateral groups, however, had significantly lower scores than children with right spastic unilateral $\mathrm{CP}^{8}$. These results confirmed those from studies by Skatvedt ${ }^{25}$ as well as Wedell ${ }^{26}$ who reported although both right and left spastic unilateral groups presented with VPI, the dominant area for visual perceptual processing in the right cerebral hemisphere resulted in those with left spastic unilateral $\mathrm{CP}$ having lower visual perceptual scores than those with right spastic unilateral $C P^{25,26}$. Some early studies used assessment tools that required motor control that could have directly impacted on the results. These studies were inconclusive as they did not clarify specific VPI deficits in children with different subtypes of $\mathrm{CP}^{27}$.

With the advent of validated assessments of visual perception which are motor free and more reliable, Stiers et al. ${ }^{20}$ completed a study on 62 participants with various subtypes of CP using the L94 visual-perceptual battery ${ }^{20}$. Most of these participants between the ages of 4 and 21 years had some form of spastic CP (I I unilateral, 49 bilateral). Forty percent of the participants presented with visual-perceptual impairment and they concluded that children with dyskinetic and ataxic CP have less severe VPI than children with spastic diplegia, quadriplegia and hemiplegia. However, there were only four participants with dyskinetic and ataxic $C P$ in their study and they reported that research specific to visual perceptual skills in this subtype of $C P$ is however very limited due to rarity of dyskinetic and ataxic $\mathrm{CP}^{20}$.

The more severe VPI in children with spastic subtypes of CP has been attributed to cortical damage where visual perceptual processing predominantly occurs ${ }^{26}$. Pueyo et al. ${ }^{28}$ confirmed the findings reported above in 2009 when they compared the visual perception of 23 participants with bilateral spastic CP and six with dyskinetic CP. They assessed visual perceptual abilities using the Benton's Facial Recognition Test and Benton's Judgment of Line Orientation Test. The participants with dyskinetic CP had significantly higher scores with $50 \%$ of participants in this group having deficits compared to the $79 \%$ of participants with bilateral spastic $\mathrm{CP}^{28}$.

No detail on the types of visual perceptual deficits were identified in the different subtypes of CP in the literature, and no literature on VPI for children with CP in South Africa was sourced. This study therefore aimed to determine the specific VPI in children with different subtypes of $C P$ attending a school for learners with special educational needs (LSEN) in Johannesburg, South Africa.

\section{METHOD}

A quantitative and cross-sectional design was used to determine the visual perceptual deficits in children with different types of CP. The data compared the participants' scores to normative data as well as the cluster of the scores and each child was assessed once $^{29}$. The study was based at Forest Town School, in Johannesburg South Africa, which is a government school for learners with special educational needs (LSEN) which caters largely for children with CP. The population for the study included children with different subtypes and a medical diagnosis of CP. Since the school caters for children with mild intellectual disability (MID), this was used as the criterion for the intellectual level for inclusion in the study. Total population sampling was used in this study and all the children in the school between ages of 4 years - 18 years, diagnosed with $\mathrm{CP}$, and who had attended occupational 
therapy for at least 6 months were included in the study. The sample size included 19 children with spastic unilateral $C P,{ }^{35}$ children with spastic bilateral $\mathrm{CP},{ }^{17}$ children with dyskinetic $\mathrm{CP}$ and 9 with ataxic CP.

\section{Research Instrument}

A demographic questionnaire was designed by the researcher to capture demographic information and included date of birth, gender, diagnosis, GMFCS level, grade, or class, whether they receive occupational therapy and the length of time they have received occupational therapy. It was also used to determine if the child met the inclusion criteria for the study. The Test of Visual Perceptual Skills $3^{\text {rd }}$ ed. (TVPS-3) was used to assess each participant. This standardized test, includes seven subtests: Visual Discrimination, Visual Memory, Spatial Relationships, Form Constancy, Visual Sequential Memory, Figure Ground, and Visual Closure $^{30}$ The TVPS-3 has been found to be a reliable and valid measure of visual perception for 4-18 year olds ${ }^{31}$. It provides a consistent measure and is relatively free of error. It has a high level of homogeneity and high test-retest reliability ${ }^{32}$. The TVPS3 provides the examiner with scores that can be analysed both for intervention and research purposes. The TVPS-3 was chosen for this study as it can be used to test children with motor or speech impairments ${ }^{30}$.

On completion of the assessment, the raw scores were converted into scaled scores and percentile ranks. The scaled scores were grouped into the appropriate index scores, which included a composite score for the overall test, Basic Processes, Sequencing and Complex Processes. These composite scores allowed the examiner to compare the skills that are related to each other, such as Basic Processes, which includes visual discrimination, visual memory, spatial relations, and form constancy; Sequencing which includes visual sequential memory and Complex Processes which includes figure-ground and visual closure. Scores were converted to standard scores and percentile ranks ${ }^{30}$.

Although the validity of using visual perceptual tests including the TVPS-3 with children with cognitive disability has been under scrutiny ${ }^{33}$ limited studies have confirmed the validity of using the TVPS-3 with typical children and those with learning disabilities in an urban South African population ${ }^{32,34}$.

\section{Research procedure}

Ethical clearance for the study was obtained from the Human Research Ethics Committee (HREC) at the University of the Witwatersrand (MI708I7) and permission to conduct the study was obtained from the Gauteng Department of Education. Class lists were screened, and therapists were consulted to identify which of the children they were treating met the inclusion criteria of the study. Consent forms, information sheets and demographic questionnaires were sent to the parents of these identified children. When parental-signed informed consent was obtained and the child met the inclusion criteria, the child was included on the list for assessment. Where the child gave witnessed verbal assent, testing was completed by the researcher who has experience in using the TVPS-3. The test was administered individually in the standardised manner, in accordance with the manual, in a quiet assessment room in Forest Town School's Occupational Therapy Department. Subtests were concluded when the child reached a ceiling and could no longer identify the correct answers after three attempts.

\section{Data Analysis}

The demographic data, subtypes of cerebral palsy and the other information related to motor function levels and education were analysed using descriptive statistics and frequencies. The frequency of the scaled scores for the TVPS-3 were calculated for the different subtypes of CP. These scores were compared for each subtest of the TVPS- 3 as well as the standard scores for the composite sections of the TVPS- 3 using the Kruskal-Wallis test to determine if a significant difference existed. The composite standard scores for the TVPS-3 were also compared according to the variables of gender, age, and motor function on the GMFCS using the Kruskal-Wallis test to determine if a significant difference -based on these variables - existed.

\section{RESULTS}

\section{Demographics}

Table I (p2I) presents the age, gender and GMFCS level demographics of the participants for different Cerebral Palsy subtypes in the study. Most participants had spastic bilateral (LL) CP, were male and fell within the age group of 9 years - 13 years II months. Only I5\% of participants were on GMFCS levels 4 and 5.

\section{Visual Perceptual Impairment in children with Cerebral Palsy}

Table II, (p2I) indicates that six out of the 80 participants (7\%) scored within normal range or above average for their age group. That means that $93 \%$ of the participants presented with overall visual perceptual difficulties and z scores below - ISD.

\section{Comparison of the Subtests of the Test of Visual Perceptual Skills $-3^{\text {rd }}$ Edition according to the Cerebral Palsy subtypes}

Table III (22) presents the results for the comparisons between the TVPS-3 subtests' overall and composite scores for the subtypes of CP. It was found that scores for the visual discrimination $(p=0.03)$ and the figure-ground $(p=0.03)$ subtests had statistically significant differences between the subtypes of $C P$. The scores for visual memory, spatial relations, form constancy, sequential memory and visual closure were not statistically significantly different when the CP subtypes were compared. When comparing the overall scores of the different subtypes of $C P$, it is evident that the spastic unilateral (right) CP subtype had the highest scores with a mean standard score of 76.55. The spastic bilateral (LL and UL) CP subtype had the second highest score, followed by spastic bilateral (LL) CP subtype, dyskinetic and spastic unilateral (left) CP subtype. The ataxic group had the lowest scores, with mean standard score of 43.55 .

There was a significant difference in the Basic Processes standard scores $(p=0.002)$ of the different subtypes of CP. The Basic processes score is comprised of visual discrimination, visual memory, spatial relations and form constancy. There was no significant difference found in the composite scores for Complex Processes and Sequencing of the different CP subtypes.

When the spastic bilateral CP subgroups were compared, the spastic bilateral (LL) CP group scored higher than the spastic bilateral ( $L L$ and $\mathrm{UL}$ ) group in the visual discrimination, visual memory, figure-ground and visual closure subtests. The spastic bilateral (LL \& UL) CP subgroup had higher scores on the spatial relationships, form constancy and sequential memory subtests. The composite scores of these two subtypes of spastic bilateral $\mathrm{CP}$ 
Table I: Demographic Information of Cerebral Palsy subtypes $(n=80)$

\begin{tabular}{|c|c|c|c|c|c|c|c|c|}
\hline \multirow{2}{*}{\multicolumn{2}{|c|}{$\begin{array}{l}\text { Subtype of } \\
\text { cerebral palsy }\end{array}$}} & $\begin{array}{l}\text { Total } \\
\text { Group }\end{array}$ & $\begin{array}{l}\text { Spastic Uni- } \\
\text { lateral (Right) }\end{array}$ & $\begin{array}{c}\text { Spastic Unilateral } \\
\text { (Left) }\end{array}$ & $\begin{array}{l}\text { Spastic Bi- } \\
\text { lateral (LL) }\end{array}$ & $\begin{array}{l}\text { Spastic Bi- } \\
\text { lateral (LL } \\
\text { and UL) }\end{array}$ & Dyskinetic & Ataxic \\
\hline & & \multicolumn{7}{|c|}{ n (\%) } \\
\hline \multicolumn{2}{|c|}{ Number of Participants } & 80 & $9(11)$ & $10(13)$ & $27(34)$ & $8(10)$ & $17(21)$ & $9(\mathrm{II})$ \\
\hline \multirow{3}{*}{$\begin{array}{l}\text { Age (Years, } \\
\text { Months) }\end{array}$} & $5 y-8 y 11 \mathrm{~m}$ & $27(33)$ & $5(6)$ & $2(2)$ & $10(12)$ & $2(2)$ & $7(8)$ & $\mathrm{I}(\mathrm{I})$ \\
\hline & $9 y-13 y \mid 1 m$ & $37(46)$ & $4(5)$ & $4(5)$ & $15(18)$ & $4(5)$ & $6(7)$ & $3(3)$ \\
\hline & $14-18 y \mid 1 \mathrm{~m}$ & $16(20)$ & $0(0)$ & $4(5)$ & $2(2)$ & $2(2)$ & $4(5)$ & $5(6)$ \\
\hline \multirow[t]{2}{*}{ Gender } & Male & $44(55)$ & $8(10)$ & $3(3)$ & $9(11)$ & $4(5)$ & $16(20$ & $4(5)$ \\
\hline & Female & $36(45)$ & $\mathrm{I}(\mathrm{II})$ & $7(8)$ & $18(22)$ & $4(5)$ & $\mathrm{I}(\mathrm{I})$ & $5(6)$ \\
\hline \multirow{5}{*}{$\begin{array}{l}\text { Gross } \\
\text { Motor Function } \\
\text { Classification } \\
\text { System Level }\end{array}$} & GMFCS I & $17(21)$ & $6(7)$ & $5(6)$ & $I(I)$ & $0(0)$ & $2(2)$ & $3(3)$ \\
\hline & GMFCS 2 & $27(34)$ & $3(3)$ & $5(6)$ & $5(6)$ & $2(2)$ & $6(7)$ & $6(7)$ \\
\hline & GMFCS 3 & $24(30)$ & $0(0)$ & $0(0)$ & $20(25)$ & $0(0)$ & $4(5)$ & $0(0)$ \\
\hline & GMFCS 4 & $8(10)$ & $0(0)$ & $0(0)$ & $I(I)$ & $5(6)$ & $2(2)$ & $3(3)$ \\
\hline & GMFCS 5 & $4(5)$ & $0(0)$ & $0(0)$ & $0(0)$ & $\mathrm{I}(\mathrm{I})$ & $3(3)$ & $0(0)$ \\
\hline
\end{tabular}

Table II: Overall Standard Scores and SD of children with Cerebral Palsy

\begin{tabular}{cccc}
\hline $\begin{array}{c}\text { Number of } \\
\text { Participants (\%) }\end{array}$ & $\begin{array}{c}\text { Standard } \\
\text { Score }\end{array}$ & z scores & $\begin{array}{c}\text { Scaled } \\
\text { scores }\end{array}$ \\
\hline $8(10)$ & $<55$ & -3 & 2 \\
$36(45)$ & $55-69$ & -2 & 4 \\
$30(38)$ & $70-84$ & -1 & 7 \\
$5(6)$ & $85-114$ & Mean & 10 \\
I (I) & $115-130$ & +1 & 13 \\
\hline
\end{tabular}

SS of $100=$ age-appropriate performance

SS of II5 = ISD above age related performance

are very similar with the spastic bilateral (LL) CP group having higher scores in the Basic Processes, Sequencing and particularly the Complex Processes.

\section{Comparison of the Composite Scores of the Test of Visual Perceptual Skills $-3^{\text {rd }}$ Ed to Gender, Age and GMFCS Level}

A significant difference was found $(p=0.031)$ in the Basic Processes standard scores of male and female participants. Males had significantly higher scores than females in the Basic Processes scores. The Sequencing standard scores $(p=0.702)$ and Complex Processes standard scores $(p=0.156)$ of males and females did not have significant differences. When looking at gender differences, Figure I indicates that males had higher standard scores in all areas including Basic Processes, Sequencing and Complex Processes.

There was no significant difference in the standard scores for the different age groups and GMFCS levels on any of the composite scores on the TVPS-3 (Table IV, p22).

\section{DISCUSSION}

South African learners from Forest Town LSEN School participated in this study and were sourced using total population sampling. A total sample of 80 learners with CP participated in the study, 55\% were male and $45 \%$ were female. The slightly higher percentage of males was supported by other studies that have found that $\mathrm{CP}$ is more common in males than in females ${ }^{35}$. The distribution of the
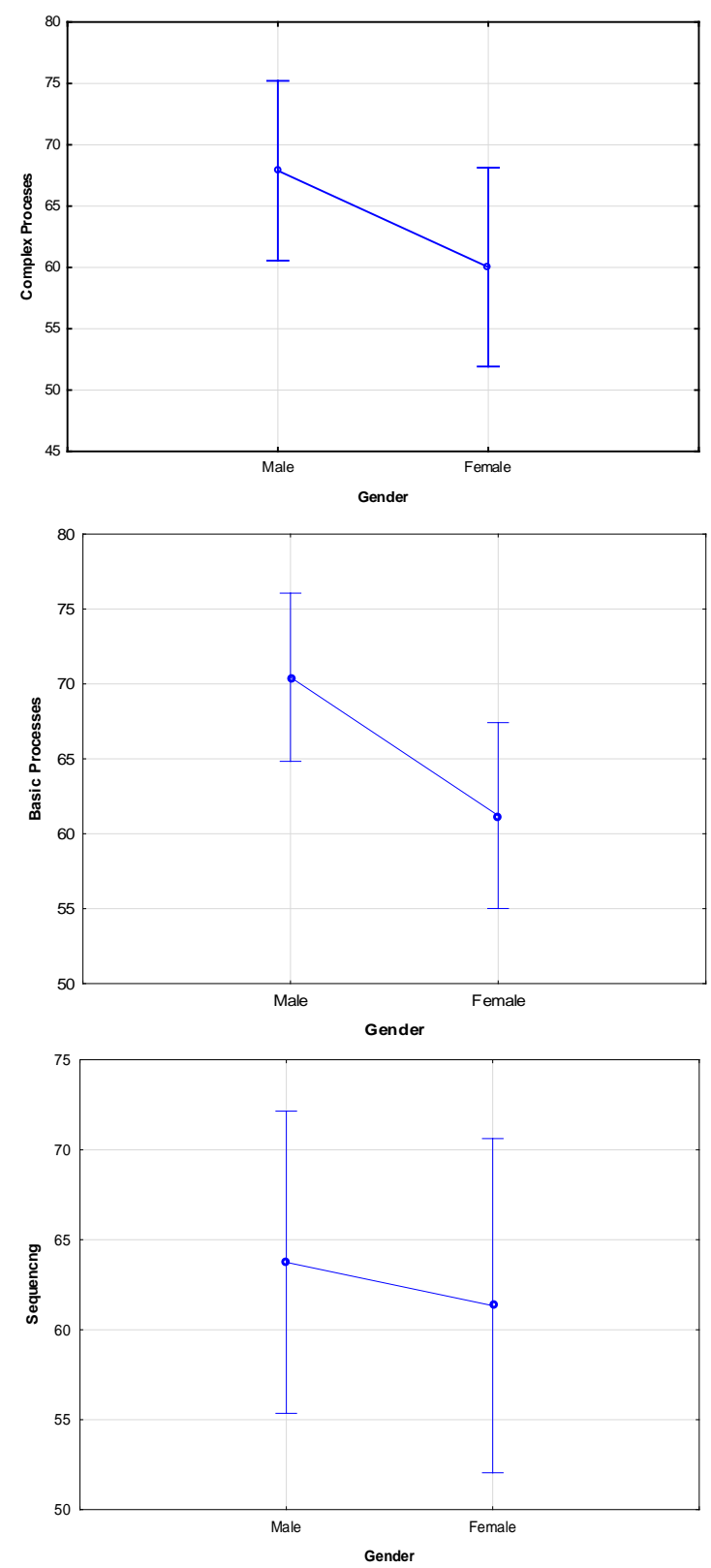

Figure I. Comparing Gender in Basic Processes. Sequencing and Complex Processes $(n=80)$ 
Table III Test of Visual Perception - $3^{\text {rd }}$ Edition subtest scaled scores, overall and composite scores in different Cerebral Palsy subtypes $(n=80)$

\begin{tabular}{|c|c|c|c|c|c|c|c|}
\hline \multirow[t]{2}{*}{ CP subtype } & $\begin{array}{c}\begin{array}{c}\text { Spastic Unilateral } \\
\text { (Right) } \\
n=9\end{array} \\
\end{array}$ & $\begin{array}{c}\text { Spastic } \\
\text { Unilateral } \\
\text { (Left) } \\
\text { n=10 }\end{array}$ & $\begin{array}{c}\text { Spastic } \\
\text { Bilateral (LL) } \\
n=27\end{array}$ & $\begin{array}{c}\text { Spastic } \\
\text { Bilateral (LL } \\
\text { and UL) } \\
\mathbf{n = 8}\end{array}$ & $\begin{array}{l}\text { Dyskinetic } \\
\qquad n=17\end{array}$ & $\begin{array}{l}\text { Ataxic } \\
n=9\end{array}$ & \multirow[t]{2}{*}{$p$ value } \\
\hline & \multicolumn{6}{|c|}{ Mean (SD) } & \\
\hline $\begin{array}{l}\text { Visual } \\
\text { Discrimination }\end{array}$ & $5.44(2.65)$ & $4.40(3.13)$ & $4.74(2.84)$ & $3.75(2.19)$ & $2.71(2.64)$ & $2.22(2.33)$ & $0.03 *$ \\
\hline Visual Memory & $5.55(3.97)$ & $3.90(4.43)$ & $4.26(3.73)$ & $3.13(3.09)$ & $3.24(3.40)$ & $1.78(2.39)$ & 0.27 \\
\hline Spatial Relationships & $6.11(3.86)$ & $3.80(4.02)$ & $4.81(3.08)$ & $5.13(3.72)$ & $3.12(2.78)$ & $2.44(2.70)$ & 0.10 \\
\hline Form Constancy & $4.11(2.26)$ & $4.10(2.77)$ & $3.81(3.66)$ & $4.50(4.44)$ & $4.47(3.48)$ & $1.78(2.11)$ & 0.33 \\
\hline Basic Processes & $76.55(12.50)$ & $65.50(12.22)$ & $71.04(12.36)$ & $70.50(13.18)$ & $63.88(19.12)$ & $43.55(33.32)$ & $0.002 *$ \\
\hline Sequential Memory & $4.22(3.19)$ & $4.20(3.6 I)$ & $4.70(2.95)$ & $5.13(2.30)$ & $3.06(2.66)$ & $2.67(2.55)$ & 0.24 \\
\hline Sequencing & $65.55(28.22)$ & $60.30(24.63)$ & 69.81 (23.99) & $69.37(28.46)$ & $53.53(32.19)$ & $52.22(31.34)$ & 0.362 \\
\hline Figure-Ground & $6.11(5.58)$ & $4.40(4.48)$ & $4.52(3.37)$ & $3.38(2.83)$ & $2.59(2.32)$ & $2.56(3.13)$ & 0.03* \\
\hline Visual Closure & $5.00(4.95)$ & $3.70(2.83)$ & $4.07(3.05)$ & $3.75(3.20)$ & $3.24(2.31)$ & $3.44(4.12)$ & 0.93 \\
\hline $\begin{array}{l}\text { Complex } \\
\text { Processes }\end{array}$ & $77.00(24.55)$ & $64.60(13.60)$ & $67.85(23.79)$ & $55.37(35.11)$ & $64.59(8.73)$ & $48.44(38.74)$ & 0.167 \\
\hline Overall & $75.89(14.46)$ & $65.10(12.10)$ & $72.11(11.52)$ & $74.87(21.15)$ & $65.82(7.23)$ & $56.33(23.46)$ & \\
\hline
\end{tabular}

Significance $p \leq 0.05 *, p \leq 0.01 * *$

Table IV Comparing Gender, Age and GMFCS in Composite Scores(n=80)

\begin{tabular}{|c|c|c|c|c|c|}
\hline & & & Basic Processes & Sequencing & $\begin{array}{l}\text { Complex } \\
\text { Processes }\end{array}$ \\
\hline \multirow[t]{3}{*}{ Gender } & Male & \multirow[t]{2}{*}{ Mean (SD) } & $70.45(16.31)$ & 63.75 (28.39) & $67.88(24.79)$ \\
\hline & Female & & $61.22(21.27)$ & $61.33(27.47)$ & $60.03(23.96)$ \\
\hline & \multicolumn{2}{|l|}{$p$ value } & $0.031 *$ & 0.702 & 0.156 \\
\hline \multirow[t]{4}{*}{ Age } & $5 y r s-8 y r s ~ I I m o$ & \multirow{3}{*}{$\begin{array}{l}\text { Mean } \\
\text { (SD) }\end{array}$} & 71.45 (9.72) & $66.25(23.18)$ & $69.50(18.62)$ \\
\hline & $9 y r s-13 y r s ~ I I m o$ & & $68.69(11.97)$ & $64.95(25.55)$ & 62.89 (24.39) \\
\hline & $14 y r s-18 y r s ~ I I m o$ & & $53.52(33.26)$ & $52.35(36.83)$ & $60.4 I(31.78)$ \\
\hline & \multicolumn{2}{|l|}{$\mathrm{p}$ Value } & 0.21 & 0.53 & 0.72 \\
\hline \multirow[t]{6}{*}{ GMFCS } & GMFCS I & \multirow{5}{*}{$\begin{array}{l}\text { Mean } \\
(\mathrm{SD})\end{array}$} & $64.82(21.50)$ & $58.70(30.73)$ & $71.23(26.02)$ \\
\hline & GMFCS 2 & & $63.78(25.19)$ & $63.33(30.00)$ & $61.18(21.65)$ \\
\hline & GMFCS 3 & & $69.33(11.50)$ & $67.50(18.53)$ & $66.20(25.16)$ \\
\hline & GMFCS 4 & & $72.87(11.32)$ & $58.12(36.74)$ & $62.00(26.01)$ \\
\hline & GMFCS 5 & & $58.25(5.68)$ & $55.00(36.97)$ & $50.00(33.65)$ \\
\hline & \multicolumn{2}{|l|}{ p Value } & 0.60 & 0.82 & 0.52 \\
\hline
\end{tabular}

Significance $p \leq 0.05^{*}$

subtypes of CP at Forest Town School was similar to that described in the literature ${ }^{3,35}$ with the nearly $70 \%$ of the participants having a diagnosis of spastic CP followed by dyskinetic (21\%) and ataxic ( I I\%) CP subtypes respectively.

\section{Visual perceptual impairment in children with Cerebral Palsy}

In this study, the prevalence of visual perceptual impairment in this population of participants with CP was $93 \%$. According to Stiers et al., the prevalence of visuo-motor and perceptual impairment can range from $39 \%$ to $100 \%$ for children with $\mathrm{CP}^{20}$, but most studies report a prevalence of $40-50 \%$ as found in the systematic review completed by Ego et al. ${ }^{3}$ The findings in the current study are similar to those of Pueyo et al. ${ }^{28}$ who found that $90 \%$ of the children with $\mathrm{CP}$ in their study had visuo-spatial impairment and $60 \%$ visuo-perceptual impairment. The high percentage found in the current study may be attributed to the chosen population being at a special needs school and thus all requiring some sort of special learning support.

In this study, the overall scores on the TVPS-3 for all the spastic $\mathrm{CP}$ subtypes were higher than the dyskinetic CP subtype except for the spastic unilateral (left) CP subtype. The participants with dyskinetic and spastic unilateral left CP subtype achieved lower scores with the lowest overall scores being achieved by the ataxic 
subtype. The visual perceptual deficits vary between the subtypes depending on the specific areas of the brain and vision that is affected. The different subtypes of $C P$ are associated with damage to different areas of the brain and the extent of deficits for each subtype is considered:

Spastic Unilateral CP- The participants with left spastic unilateral $C P$ had consistently lower scores on all subtests and composite scores than those with right spastic unilateral CP. This was supported by Wedell ${ }^{26}$ who suggested this finding was accounted for by damage to the right cerebral hemisphere since right side of the brain is dominant for visual perceptual processing. Visual perceptual impairment is therefore more likely to occur in children with left spastic unilateral $\mathrm{CP}^{34}$. Lidzba et al. ${ }^{10}$. reported similar differences in visuospatial perception on the Rey Osterrieth Copy test ${ }^{36}$ and the Tube Figures test ${ }^{37}$ for adolescents and young adults with left spastic unilateral CP. They supported this finding by suggesting language "crowding" in the right hemisphere as a result of alternate language development in that hemisphere, also affects the perceptual ability in those with left spastic unilateral $C P^{10}$

Spastic Bilateral CP-The results for this subtype of CP, indicate that the extent of physical dysfunction does not necessarily impact on the visual perceptual scores of the participants with $\mathrm{CP}$, supported by research completed by Hamid et al. ${ }^{9}$. However, in the current study the participants with spastic bilateral (LL \& UL) CP had a higher overall score on the TVPS -3 than the participants with spastic bilateral (LL) CP. There is some controversy since Menken, Cermak and Fisher ${ }^{27}$, reported that children with spastic bilateral (LL \& UL) CP had lower scores on the TVPS while Stiers et al. ${ }^{20}$ (using the L94 tasks) found that the children with spastic bilateral (LL \& UL) CP had higher scores than children with spastic bilateral (LL) CP and spastic unilateral left CP. However, the L94 is a computer based test with items which differ from the TVPS $-3^{38}$. This confirms the findings in the current study, that children with spastic bilateral (LL \& UL) CP and children with spastic bilateral (LL) CP may have different deficits depending on the specific tests used and the specific subtests assessed on the TVPS-3.

In the current study the spastic bilateral (LL \& UL) CP subgroup had higher scores on the spatial relationships, form constancy and sequential memory subtests. However, the spastic bilateral (LL) CP group had higher scores than the spastic bilateral ( $L L$ and $U L$ ) group in the visual discrimination, visual memory, figure-ground and visual closure subtests. The spastic bilateral (LL) CP group had higher scores in the Basic Processes, Sequencing and particularly the Complex Processes. Although other studies found that children with dyskinetic and ataxic CP had higher visual perceptual scores than all the children with different subtypes of spastic CP none of these studies used the motor free TVPS-38,38. The children with dyskinetic and ataxic CP had lower scores than the children with spastic CP subtypes.

Dyskinetic CP-All the scores for the dyskinetic CP group fell at -2 SD and -3 SD below the mean. Their lowest scores were on visual discrimination in Basic Processes and figure-ground in Complex Processes. Both these TVPS- 3 subtests require the participant to focus on the very intricate details to either discriminate between the objects or to find the objects in very busy, distracting backgrounds. Visual impairment difficulties could contribute to these poor scores since Ipata et al. ${ }^{39}$ found that children with dyskinetic $\mathrm{CP}$ had the highest incidence of visual impairment. Children with dyskinetic $C P$ often present with dyskinetic strabismus ${ }^{40}$ which could be a contributing factor to the low visual perceptual scores of the participants in this group. Poor visual acuity and difficulty controlling eye movements would cause this test to be very difficult and even affect the results ${ }^{41}$. All the scores for participants with dyskinetic $\mathrm{CP}$ were higher than those of the ataxic group except for visual closure.

Ataxic CP- On the TVPS-3 results of the ataxic subgroup, the scores for all the subtests fell -2 SD below the mean, thus indicating visual perceptual impairment. Many children with ataxic CP have cerebellar ocular nystagmus ${ }^{18}$ and this results in difficulty with scanning, tracking and focusing and could be one of the contributing reasons to the ataxic CP groups' low subtests and composite scores. The lowest scores for this subtype group were for visual memory and form constancy. Limited research is available on visual perceptual impairment in ataxic CP due to its rarity ${ }^{20}$ with many studies having far fewer participants with ataxic $C P$ than this study.

The findings in this study do not correlate with the findings of other studies which concluded that visual perceptual impairment is associated with $\mathrm{CP}$ where spasticity is dominant ${ }^{8,20}$. However, the ataxic group in this study were older and in the modified section in the school so may have presented with added cognitive difficulties as they were unable to follow the academic programme. Sigurdardottir et al. ${ }^{42}$, in a study on 127 Icelandic children with CP, found with dyskinetic and ataxia $\mathrm{CP}$ still requiring support services into adolescence presented with more cognitive difficulties ${ }^{42}$. Although visual perception has not been strongly associated with intelligence ${ }^{43}$ in children with CP this finding may account for the result for the majority of the ataxia participants in the current study

The analysis of VPI in children with $\mathrm{CP}$ according to demographic factors indicated a significant difference $(p=0.03 \mathrm{I})$ in the Basic Processes scores of male and female participants, with males scoring higher than females. There were no significant differences between Sequencing and Complex Processes scores. Stadskleiv et al. ${ }^{42}$ also found higher cognitive scores for males with CP in their study, but the gender difference was not significant ${ }^{44}$. Although the tests are considered to be gender free in certain circumstances, it appears that there may be differences between genders in South African children, but other studies did not consider this variable so comparisons cannot be made ${ }^{32}$. Smith et al. ${ }^{45}$ completed a study where they looked at the considerations when assessing South African children using standardised visual perception tests using the Developmental Test of Visual Perception $2^{\text {nd }}$ Edition. In their study, males and females had similar scores on all the subtests of the DTVP-2 except the figure-ground subtest which had a significant difference $(p=0.03)$, with females scoring higher than males ${ }^{45}$.

No significant differences for age were found in this study for Basic Processes, Sequencing and Complex Processes scores. In all the index scores, a trend that younger participants appeared to have slightly higher scores than older participants, was noted. This could be attributed to younger children having more exposure to therapy at the school which considers visual perceptual impairments. Stadskleiv et al. ${ }^{44}$ confirmed in their study on neuropsychological profiles of children with $\mathrm{CP}$, that older children and adolescents had a lower average performance on standardised tests than younger age groups attending rehabilitation at a hospital ${ }^{44}$. Again, it is possible that only older participants with more deficits were retained in the programme. When motor function was considered there was no significant differences in the visual perceptual scores of the different GMFCS levels. The GMFCS level 4 participants scored the highest in the Basic Processes composite scores and the scores of the GMFCS level 3 participants were highest in the sequencing composite scores. These results correlate with the 
research completed by Hamid et al. ${ }^{9}$ where they found that the severity of gross motor functioning does not directly impact on the visual perceptual skills of children with $\mathrm{CP}^{9}$

\section{LIMITATIONS}

The acuity and eye movements of the participants were not considered in this study and therefore, a comparison between their visual impairment and their visual perceptual scores could not be made. The results for visual perceptual skills of the current study have been considered in relation to the reported visual impairment by subtype in the literature.

The sample in this study had different number of participants in each CP subtype and the small number of participants in some groups may have affected the results. However, the number did reflect the prevalence of $\mathrm{CP}$ subtypes and the number of participants seen in other studies.

\section{CONCLUSION}

This study aimed to describe the differences between the specific VPIs in children with different subtypes of CP attending a school for learners with special educational needs (LSEN) in Johannesburg. The results in this study found that learners with all subtypes of CP have VPI which indicates that all children with CP should be assessed for visual perceptual deficits as many of them may require therapy for visual perceptual deficits.

The spastic unilateral (right) CP groups had the highest overall scores and the ataxic group had the lowest scores. The different subtypes of CP showed different trends in VPI. There was a significant difference in the visual discrimination and figure-ground subtest scores as well as the composite Basic Processes scores between the different subtypes of CP as well as between males and females. Participants with unilateral spastic $\mathrm{CP}$ had greater impairment in sequential memory and spatial components while the participants with bilateral spastic $\mathrm{CP}$ had greater impairments in visual discrimination related components. No significant differences are found between different ages and GMFCS levels.

\section{RECOMMENDATIONS}

The results of this study have implications for future clinical practice with children with CP in an LSEN school in South Africa. Due to the findings that almost all the children with CP have VPI, practitioners working with children with CP need to be aware of these impairments and provide appropriate accommodations or compensations for these impairments not only when working on VP skills, but also in day-to-day life, as they have a major impact on function and ADLs. The trends that were found in this study can assist with the grouping of CP subtypes in therapy. The extent of VPI of the different subtypes of CP were identified and therefore in this setting children can be grouped accordingly. This should however be done with caution and individual treatment for children should still be administered where possible.

\section{Recommendations for further research}

Further research is required when considering VPI in children with CP in a South African context. It is recommended that future studies on VPI in children with CP, be completed on a larger population and in a variety of different schools in order to further validate these results. Qualitative studies could further identify the way in which occupational therapists could design interventions to address the VPIs found in this study.
Future research that takes visual impairment into consideration when assessing VPI in children with CP would be beneficial. Thus, a comparison between the extent of visual impairment and VP scores could be compared to determine the impact that vision has on VP scores.

\section{ROLE OF AUTHORS}

Sharna Berelowitz - postgraduate student who conceptualised and completed the research - conceptualisation and contribution to the article.

Denise Franzsen - supervisor of the project - data analysis and conceptualisation of results and discussion - conceptualisation and contribution to the article

\section{REFERENCES}

I. Eunson P. Aetiology and epidemiology of cerebral palsy. Paediatrics and Child Health (United Kingdom). 2016;26(9): 367-372. http://doi.org/I0.1016/j.paed.2016.04.01 I

2. Schmetz E, Magis D, Detraux JJ, Barisnikov K, Rousselle L. Basic visual perceptual processes in children with typical development and cerebral palsy: The processing of surface, length, orientation, and position. Child Neuropsychology. 2019;25(2): 232-262. http://doi.org/10.1080/09297049.2018.1441820

3. Ego A, Lidzba K, Brovedani P, Belmonti V, Gonzalez-Monge S, Boudia $B$, et al. Visual-perceptual impairment in children with cerebral palsy: A systematic review. Developmental Medicine and Child Neurology. 2015;57(s2): 46-5I. http://doi.org/I0.1।II/ dmcn. 12687

4. Tsai LT, Lin KC, Liao HF, Hsieh CL. Reliability of two VisualPerceptual tests for children with cerebral palsy. American Journal of Occupational Therapy. 2009;63(4): 473-480. http://doi.org// 0.5014/ajot.63.4.473

5. Case-Smith J, O'Brein JC. Occupational Therapy for Children.. $6^{\text {th }}$ Editio. Elsevier; 2010.

6. Ramkumar S, Gupta A. A Study on Effect of Occupational Therapy Intervention Program Using Cognitive-Perceptual and Perceptual-Motor Activities on Visual Perceptual Skills in Children with Cerebral Palsy. Indian Journal of Physiotherapy and Occupational Therapy. 2016;10(3): 60. http://doi.org/10.5958/09735674.2016 .00083 .6

7. Cho M, DeokJu K, Yeongae Y. Effects of visual perceptual intervention on visual-motor integration and activities of daily living performance of children with cerebral palsy. Journal of Physical Therapy Science,27(2). 20I5;27(2): 4II-4I3.

8. Abercrombie MLJ. Perceptual and Visuo-Motor Disorders in Cerebral Palsy. Pediatrics. 1964;34(5): 745-745.

9. Hamid D, Mostafa E, Saeid F, Allah HH, Akbar B. Comparison of Visual Perceptual skills in children with cerebral palsy based on the severity of gross motor function. Journal of Clinical Research in Paramedical Sciences. 2016;5(2): 155-163.

10. Lidzba K, Staudt M, Wilke M, Krägeloh-Mann I. Visuospatial deficits in patients with early left-hemispheric lesions and functional reorganization of language: Consequence of lesion or reorganization? Neuropsychologia. 2006;44(7): 1088-1094.

http://doi.org/10.1016/j.neuropsychologia.2005.10.022

I I. Koeda T, Takeshita K. Visuo-Perceptual Impairment and Cerebral Lesions in Spastic Diplegia with Preterm Birth. Brain and Development. 1992; I4(4): 239-244. http://doi.org/10.1016/S0387-7604(12)80237-3

12. Davies L. Current occupational therapy and physiotherapy practice in implementing home programmes for young children with cere- 
bral palys in South Africa. University of the Witwatersrand; 2016. Available from: http://wiredspace.wits.ac.za/handle/I0539/21369

13. Cans C. Surveillance of cerebral palsy in Europe: a collaboration of cerebral palsy surveys and registers. Developmental Medicine and Child Neurology. 2007;42(12): 816-824.

http://doi.org/10.1 I I I/j.1469-8749.2000.tb00695.x

14. Van den Broeck C, Himpens E, Vanhaesebrouck P. Influence of gestational age on the type of brain injury and neuromotor outcome in high-risk neonates. European Journal of Pediatrics. 2007; 17(9): 1005-1009.

15. Waters F. Understanding cerebral palsy-a guide for parents and professionals. International Journal of Disability, Development and Education. 2013;60(2): 173-174.

http://doi.org/10.1080/10349I2x.2013.786570

16. Koman L, Smith B, Shilt J. Cerebral palsy. Lancet. 2004;363: |619-1631. http://doi.org/10.1016/b978-0-444-52901-5.00038-|

17. Turlough Fitzgerald MJ, Gruener G, Mtui E. Clinical Neuroanatomy and Neuroscience. Clinical Neuroanatomy and Neuroscience. 6th ed. Elsevier Saunders; 2012. p. 349-350.

18. Ferrari A, Cioni G. The Spastic forms of cerebral palsy: A guide to the assessment of adaptive functions. The Spastic Forms of Cerebral Palsy: A Guide to the Assessment of Adaptive Functions. Dordrecht, 2010. I-359 p. http://doi.org/10.1007/978-88-4701478-7

19. Rosenbaum P, Paneth N, Leviton A, Goldstein M, Bax M, Damiano $D$, et al. A report: the definition and classification of cerebral palsy. Developmental Medicine and Child Neurology. 2006; 109(suppl 109): 8-14.

20. Stiers P, Vanderkelen R, Vanneste G, Coene S, De Rammelaere $M$, Vandenbussche $E$. Visual-perceptual impairment in a random sample of children with cerebral palsy. Developmental Medicine and Child Neurology. 2002;44(6): 370-382.

http://doi.org/I0.1 I I I/j. I469-8749.2002.tb0083I.x

21. Van Den Hout BM, De Vries LS, Meiners LC, Stiers P, Van Der Schouw YT, Jennekens-Schinkel A, et al. Visual perceptual impairment in children at 5 years of age with perinatal haemorrhagic or ischaemic brain damage in relation to cerebral magnetic resonance imaging. Brain and Development. 2004;

http://doi.org/10.1016/S0387-7604(03)00163-3

22. Kozeis N, Anogeianaki A, Mitova DT, Anogianakis G, Mitov T, Klisarova A. Visual function and visual perception in cerebral palsied children. Ophthalmic and Physiological Optics. 2007;27(I): 44-53. http://doi.org/I0.1 I I I/j. I475-I3 |3.2006.004 I3.x

23. Fazzi E, Bova SM, Uggetti C, Signorini SG, Bianchi PE, Maraucci I, et al. Visual-perceptual impairment in children with periventricular leukomalacia. Brain and Development. 2004;26(8): 506-5I2. http://doi.org/10.1016/j.braindev.2004.02.002

24. Schenk T, Mcintosh RD. Do we have independent visual streams for perception and action? Cognitive Neuroscience 2010; I ( I): 52-78. http://doi.org/10.1080/17588920903388950

25. Skatvedt M. Sensory perceptual and other non-motor deficits in cerebral palsy. Child Neurology and Cerebral Palsy. London: William Heinemann; 1960.

26. Wedell K. The Visual Perception of Cerebral Palsied Children. Journal of Child Psychology and Psychiatry. 1960; I (3): 215-227. http://doi.org/10.1 III/j.1469-7610.1960.tb01995.x

27. Menken C, Cermak SA, Fisher A. Evaluating the Visual-Perceptual Skills of Children With Cerebral Palsy. American Journal of Occupational Therapy. 1987;4I(10): 646-65I.

http://doi.org/10.5014/ajot.4I.10.646

28. Pueyo R, Junique C, Vendrell P, Narberhaus A, Segarra D. Neu- ropsychologic impairment in bilateral cerebral palsy. Pediatric Neurology. 2009;40(1): 19-26.

29. Da Silva L (20I I) Quantitative Research Methods and Tools. Available at: http://www.fraserhealth.ca/media/20I I_I I_I4_Quantitative-Research-Methods-and-Tools.pdf

30. Martin N. Test of Visual Perceptual Skills.. $3^{\text {rd }}$ ed. Los Angeles: Academic Therapy Publications; 2006.

3I. Brown T, Elliot S, Bourne R, Sutton E, Wigg S, Morgan D. Test of Visual Perception - Adolescent and Adult , and Test of Visual Perceptual Skills ( non-motor ) - third edition when used with adults. 2012;75(March 201 I): I34-143. h http://doi.org//0.4276/0308022 I 2X133 I I 19571783

32. Visser M, Nel R, Jansen T, Kinmont L, Terblanché S, van Wyk J. Visual perception of five-year-old English-speaking children in Bloemfontein using the Beery VMI-6, DTVP-3 and TVPS-3. South African Journal of Occupational Therapy. 2017;47(2): 17-26. http://doi.org/10.17159/231-3833/1017/v47n2a4

33. Brown T. The Concurrent Validity of Three Visual Perception Tests Used with Adults. Occupational Therapy In Health Care. 2009;23(2): 99-II8.

34. Harris M. The Validity and Reliability of Visual Perceptual Standardised Tests in Children from the Gauteng Province, South Africa. 2017.

35. Johnston M V., Hagberg $\mathrm{H}$. Sex and the pathogenesis of cerebral palsy. Developmental Medicine and Child Neurology. 2007;49(I): 74-78. http://doi.org/10.1017/S0012162207000199.x

36. Rey A. L'examen psychologique dans les cas d'encéphalopathie traumatique. (Les problems.). [The psychological examination in cases of traumatic encepholopathy. Problems.]. Archives de Psychologie. 1941; 28(2): 215-285.

37. Stumpf, H. \& Fay E. Tube Figures test Schlauchfiguren. Gottingen: Hogrefe; 1983.

38. Stiers P, De Cock P, Vandenbussche E. Impaired visual perceptual performance on an object recognition task in children with cerebral visual impairment. Neuropediatrics. 1998;29(2): 80-88. http://doi.org/l0.1055/s-2007-973540

39. Ipata AE, Cioni G, Bottai P, Fazzi B, Canapicchi R, Duin JVH. Acuity card testing in children with cerebral palsy related to magnetic resonance images, mental levels and motor abilities. 1994; Brain and Development, 16(3), pp.195-203.

https://doi.org/10.1016/0387-7604(94)90069-8.

40. Ghasia F, Brunstrom J, Gordon M, Tychsen L. Frequency and severity of visual sensory and motor Deficits in children with cerebral palsy: Gross motor function classification scale. Investigative Ophthalmology and Visual Science. 2008;49(2): 572-580.

http://doi.org/10.1 167/iovs.07-0525

4I. Ibrahimi D, Mendiola-Santibañez JD, Gkaros AP. Analysis of the potential impact of strabismus with and without amblyopia on visual-perceptual and visual-motor skills evaluated using TVPS-3 and VMI-6 tests. Journal of Optometry. 2020;(article i. http://doi.org// 0.1016/j.optom.2020.04.002

42. Sigurdardottir S, Eiriksdottir A, Gunnarsdottir E, Meintema M, Arnadottir U, Vik T. Cognitive profile in young Icelandic children with cerebral palsy. Developmental Medicine and Child Neurology. 2008;50(5): 357-362. http://doi.org/10.1 I I I/j. 1469-8749.2008.02046.x

43. Critten V, Campbell E, Farran E, Messer D. Visual perception, visual-spatial cognition and mathematics: Associations and predictions in children with cerebral palsy. Research in Developmental Disabilities. 2018;80(7): 180-191. http://doi.org/10.1016/j. ridd. 2018.06 .007 
44. Stadskleiv K, Jahnsen R, Andersen G, von Tetzchner S. Neuropsychological profiles of children with cerebral palsy. Developmental Neurorehabilitation. 2018;2I(2): 108-120.

http://doi.org/I0.1080/I75I8423.2017.1282054

45 Smith, M., Visser, M.M., van Heerden, R. and Raubenheimer, J., 2018. Considerations when assessing urban South African children with the Developmental Test of Visual Perception 2nd edition (DTVP-2). South African Journal of Occupational Therapy, 48(I), pp.5I-59.http://dx.doi.org/10.17/59/23 I0-3833/20I7/vol48n la9

\section{Corresponding Author}

\section{Shama Berelowitz}

Email: shamaberelowitz@gmail.com 